\title{
The Formation of Inflation Expectations
}

\author{
DAVID H. RESLER
}

$\mathrm{T}$ HE psychology of inflation is often cited as a major barrier in the war against inflation. One currently popular view contends that anti-inflation policies must not only attack the causes of inflation but also lower inflation expectations. In 1971, the Nixon Administration used this argument to justify the imposition of wage and price controls. More recently, President Carter's March 14 economic policy initiative was intended, in part, to calm financial markets by signaling that inflation expectations should be lowered. Similarly, the objective of lowering inflation expectations has also been used to justify proposed inflation remedies such as the tax-based incomes policy (TIP). ${ }^{1}$

Concern over inflation expectations has been motivated primarily by recent developments in macroeconomic theory that place the expectations of important economic variables at the forefront of analysis. For instance, many economists attribute the existence of the so-called Phillips curve trade-off between inflation and unemployment to unrealized inflation expectations rather than to inflation per se. ${ }^{2}$

Although inflation expectations have become crucial to both theoretical and policy analysis, they remain extraordinarily difficult to measure. Generally,

1For a discussion and analysis of the TIP program see Nancy Ammon Jianakoplos, "A Tax-Based Incomes Policy (TIP): What's It All About?" this Review (February 1978), pp. 8-12

Milton Friedman, in his 1977 Nobel Laureate address, details the intellectual evolution of various theories of the inflationunemployment trade-off. See Friedman, "Nobel Lecture: Inflation and Unemployment," Journal of Political Economy (June 1977), pp. 451-72. economists have relied on various distributed lag models of past inflation rates to estimate inflation expectations. To a lesser extent, they have employed data gathered from surveys of economists, such as those conducted semiannually by Joseph Livingston of the Philadelphia Inquirer, or from surveys of households, such as those conducted by the Institute for Social Research of the University of Michigan. ${ }^{3}$ Although most studies using these data do so to test alternative hypotheses about economic activity, other scholars have been concerned with the actual process by which price expectations are generated, ${ }^{4}$

Forecasts of inflation can be modeled in various ways. One simple approach formulates the inflation forecast based solely on the history of inflation. As noted above, variations of such autoregressive schemes have dominated studies that include measures of inflation expectations. If independently determined forecasts of inflation are available, then one could test whether only the history of infla-

\$See Joseph Livingston, (biannual surveys), Philadelphia Sunday Bulletin, June and December, 1948-1971 and Philadelphita Inquiter, June and Decermber, 1972 to the present; and Richard T. Curtin, ed., Surveys of Consumers 1974-75, Contributions to Behavioral Economics (Ann Arbor: Institute for Social Research, The University of Michigan, 1976 ).

Some studies that have focused on this process include James Pesando, "A Note on the Rationality of the Livingston Price Expectations," Journal of Political Economy (August 1975), pp. 849 58; John A. Carlson, "A Study of Price Forecasts", Annals of Economic and Social Measurement (June 1977), pp. 27-56; Donald J. Mullineaux, "Inflation Expectations and Money Growth in the United States," American Economic Review (March 1980), pp. 149-161; and Edward J. Kane and Burton G. Malkiel, "Autoregressive and Nonautoregressive Elements in Cross-Section Forecasts of Inflation," Econometrica (January 1976), pp. 1-16. 
tion is important in explaining those forecasts. AIternately, "rational expectations" hypotheses argue that all currently available information relevant to the actual inflation process is considered when forecasts are made. Although such information would not be confined solely to the history of inflation, the set of relevant information may be dominated by it. In this case, again, inflation expectations would be closely approximated by some autoregressive scheme.

Related to the process that generates inflation expectations is the mechanism by which revisions in expectations are determined as new information becomes available. Knowledge of whether such revisions are systematically related to recent forecasts is useful in assessing the impact that inflation expectations have on economic activity. The simplest hypothesis is that revisions in forecasts depend on past forecast errors. "This approach implicitly assumes that all information relevant to the forecast revision is contained in the most recent forecast error. As Mincer has noted, such error-learning models can be interpreted as a reduced form of an autoregressive forecasting model. ${ }^{6}$ If the actual inflation forecasting process is not described solely by the history of inflation, however, then exclusive reliance on past forecast errors to describe expectations revisions would be inappropriate.

This article investigates the process by which inflation expectations are formed and the relevance of error-learning models for analyzing revisions in these expectations, using the Livingston survey data. The extent of error-learning in the revision of inflation expectations, as well as the process by which these expectations are formed, offers useful clues about the efficacy of inflation-reducing strategies.

\section{INFLATION EXPECTATIONS AND FORECAST REVISIONS: THE LIVINGSTON DATA}

Twice each year, Joseph Livingston, a financial reporter for the Philadelphia Inquirer, requests selected business, government, and academic economists to provide forecasts of various measures of economic activity, including levels of the Consumer Price Index

5David Meiselman pioneered the use of the "error-leaming" model in his study, The Term Structure of Interest Rates (Englewood Cliffs: Prentice-Hall, 1962).

'See Jacob Mincer, "Models of Adaptive Forecasting," in Economic Forecasts and Expectations, Jacob Mincer, ed. (New York: National Bureau of Economic Research, distributed by Columbia University Press, 1969).
(CPI). John Carlson used Livingston's data on these price level forecasts to generate a series on inflation expectations for the period from 1947 to 1975.7 For this article, these data have been updated through 1978 using Carlson's methodology.

Although calculations of inflation expectations can be derived directly from price level forecasts, calculations of revisions in these expectations require information about inflation forecasts that were made over different time horizons. Since the price expectations reported by Livingston are for 6 - and 12 month horizons, it is easy to calculate a rate of inflation expected over the 6-month period beginning six months hence, Specifically, for the succeeding 6month period, the inflation rate implied by the current 6- $\left(\pi^{*}\right)$ and 12-month ( $\left.\pi_{12}^{*}\right)$ inflation forecasts can be described as:

$$
f_{B_{1} \pm}=\frac{\left(1+\pi_{12, t}^{*}\right)^{2}}{\left(1+\pi_{t, t}^{*}\right)}-1
$$

The forecast revision, $R_{t}$, is then defined as:

$$
\mathbf{R}_{\mathbf{t}}=\mathbf{T}_{\mathrm{a}, \mathrm{t}}^{*}-\mathbf{f}_{\mathrm{s}, \mathrm{t}-\mathrm{i}},
$$

where the $t$ subscripts identify the moment at which the expectations (or the implied forward inflation rate) are formed.

\section{INFLATION EXPECTATIONS AND FORECAST REVISIONS: PREVIOUS STUDIES}

Pesando and Mullineaux, among others, have used either the predictions published by Livingston or those revised by Carlson to estimate equations that

For details of how the expected rate of inflation is calculated from the Livingston price level forecasts, see Carlson, "A Study of Price Forecasts."

sActually, Carlson calculated an implied inflation rate for an 8- and 14-month horizon. An example will clarify this point. The Livingston survey respondents are asked, prior to, say, the June survey, to forecast the level of the CPI for the comm. ing December and the following June. Since this forecast is made a month or more prior to the survey's publication, Carl son assumed that most respondents would know only the level of the CPI data two months before (April or October) the survey's publication. Thus the economists were forecasting the CPI for 8 and 14 months ahead. In this article, these forecasts are described as 6 - or 12 -month forecasts but are, in fact, identical to those of Carlson. This means that the forecast inflation rates for 6- and 8-month and for 12- and 14-month horizons are assumed to be the same.

In general, the implied $j$-month inflation rate for the interval from i to $i+1$ is:

$$
f_{1,1}=\frac{\left(1+\pi_{1 \cdot(1+1)}^{a}\right)^{1+1}}{\left(1+\pi_{1 \cdot 1}^{6}\right)^{i}}-1
$$

This expression is similar to that used in the term-structure of interest rate literature to describe the implied forward interest rate. 


\begin{tabular}{|c|c|c|c|c|c|}
\hline \multirow[b]{2}{*}{ Period } & \multicolumn{2}{|c|}{ Coefficients ${ }^{\text {R }}=$} & \multirow[b]{2}{*}{$\mathrm{R}^{2} / \overline{\mathrm{A}}^{2}$} & \multirow[b]{2}{*}{ SEE } & \multirow[b]{2}{*}{ DW. } \\
\hline & $b_{i}$ & b. & & & \\
\hline $1953-62$ & $(-.318)$ & $(045)$ & $.013 /-042$ & 568 & 1.013 \\
\hline $1963-71$ & $\begin{array}{c}-264 \\
(-2,458)\end{array}$ & $\frac{085}{(1227)}$ & $0861 / 029$ & 327 & $1.550^{\circ}$ \\
\hline $1953-71$ & $(-1.458)$ & $\begin{array}{l}056 \\
(926)\end{array}$ & $023 /-004$ & 466 & 1.072 \\
\hline $1953-75$ & $(-2.287$ & $\begin{array}{c}208 \\
(4.075)\end{array}$ & $274 / 258$ & 539 & $1.513^{\circ}$ \\
\hline $1953-78$ & $\begin{array}{r}-.305 \\
(-3.319)\end{array}$ & $(4.550)$ & $293 / 279$ & .525 & $1.569^{\circ}$ \\
\hline $\begin{array}{l}1953-78 \\
\text { (omiting } \\
1972-74)\end{array}$ & $\begin{array}{r}-250 \\
(-2.630)\end{array}$ & $\begin{array}{r}118 \\
(1.991)\end{array}$ & 0831062 & 514 & 1.509 \\
\hline
\end{tabular}

4 -statistics are in parentheses.

bValue of Durbin Watson statistie penmits rejection of positive sertal contelation.

Value of Durbin Watson statistie is in the indeterminate range

"explain" the forecasts in terms of observable economic variables, such as past actual rates of inflation, past rates of money growth, and so on. Most of these studies sought to investigate the rationality and effi. ciency of inflation forecasts. None have investigated explicitly the process by which forecasters revise their expectations.

Although Carlson did not explicitly examine the process by which inflation forecasts are formed, he did investigate the relevance of a simple error-learning model in explaining forecast revisions. He did not, however, derive his error-learning model from some underlying structural forecasting model. Consequently, his finding of only weak evidence that past forecast errors affected revisions in expectations warrants reexamination.

Carlson argued that forecast revisions depend on the most recent forecast error $\left(E_{t}\right)$ in inflation expectations. This error is defined as:

$$
E_{t}=\pi_{e, t}-\pi_{t, t-1, t}^{t}
$$

where $\pi_{6, \mathrm{t}}$ is the most recent 6 -month rate of inflation observed at time $t$. Carlson then investigated the error-learning hypothesis by estimating the equation:

$$
\mathbf{R}_{\mathbf{t}}=\mathrm{b}_{\mathrm{s}}+\mathrm{b}_{\mathrm{s}} \mathrm{E}_{\mathrm{t}}+\mathrm{u}_{\mathrm{t}}
$$

where $u_{t}$ is a random error. This equation states that revisions of previous forecasts depend only on the most recent forecast error.

Carlson's estimations of equation 4 over three different sample periods (1953-62, 1963-71, and 1953-71) failed to uncover any consistent evidence in support of the error-learning hypothesis. Although he found some evidence of error-learning in inflation forecasts based on the Wholesale Price Index (WPI), he found no evidence that error-learning significantly affected revisions of 6-month inflation forecasts based on semiannual observations of the CPI.

To test whether this conclusion remains valid when more recent data are included, equation 4 was reestimated over selected time periods. The results, reported in table 1 , do not support Carlson's conclusion when the sample period is extended to include the 1970s. For example, the estimated coefficient on past errors is positive and significant when the equation is estimated through 1975 or 1978.

Because the pervasive price controls in effect dur- 


\section{Table 2}

\section{Revisions in Inflation Expectations: The Carlson Model (Cochrane-Orcutt estimation)}

\begin{tabular}{|c|c|c|c|c|c|c|}
\hline \multirow[b]{2}{*}{ Period } & \multicolumn{2}{|c|}{ Coefficients } & \multirow[b]{2}{*}{$\mathrm{A} / \mathrm{R}^{2}$} & \multirow[b]{2}{*}{ SEE } & \multirow[b]{2}{*}{ D.W } & \multirow[b]{2}{*}{ Rho $^{\text {' }}$} \\
\hline & $b_{0}$ & $b_{1}$ & & & & \\
\hline $1953-62$ & $\begin{array}{r}-149 \\
(-651)\end{array}$ & $\begin{array}{r}086 \\
(1,17)\end{array}$ & $259 / / 215$ & 493 & 1967 & $\begin{array}{r}482 \\
(2,396)\end{array}$ \\
\hline $1953-71$ & $\begin{array}{r}-218 \\
(-1642)\end{array}$ & $\begin{array}{r}077 \\
(1.450)\end{array}$ & $191 / 168$ & 420 & 1860 & $\begin{array}{r}432 \\
(2912)\end{array}$ \\
\hline $1953-78$ & $\begin{array}{r}333 \\
(-3,161)\end{array}$ & $\begin{array}{l}220 \\
(4684)\end{array}$ & $340 / 327$ & 508 & 2.024 & $\begin{array}{r}194 \\
(1.413)\end{array}$ \\
\hline $\begin{array}{l}1953-78 \\
\text { (omitting } \\
1972-74 \text { ) }\end{array}$ & $\begin{array}{r}-2268 \\
(-2.238)\end{array}$ & $\begin{array}{r}114 \\
(2.263)\end{array}$ & $142 / 1122$ & 440 & 1758 & $\begin{array}{r}245 \\
(1.674)\end{array}$ \\
\hline
\end{tabular}

t-statistics are in parentheses.

The autocorrelation coefficient as estimated by the Cochrane-Orcutt technique, t-statistics are in parentheses

ing the period 1972-74 may have distorted the effect of past errors, equation 4 was estimated through 1978 omitting 1972-74 data. Again, the hypothesis that error-learning has been an important factor in the formation of inflation expectations cannot be rejected.

The low Durbin-Watson (D.W.) statistics for several versions of equation 4 suggest the presence of serially correlated residuals $\left(\mathrm{u}_{\mathrm{t}}\right)$. As a result, estimates of equation 4 may not be efficient. The Cochrane-Orcutt iterative technique was used to correct for the presence of attocorrelation for those sample periods in which the D.W. statistic indicated that the hypothesis of serially correlated residuals could not be conclusively rejected. Estimates of equation 4, using this method, are reported in table 2 and, like those discussed above, are less conclusive than Carlson's about the relevance of the error-learning hypothesis. For example, in the 1953-71 period, the t-statistic for the coefficient on the forecast error, though small, is significent at the 10 percent confidence level using a one-tailed test. ${ }^{10}$ Nevertheless, over the two subsamples of the period, 1953-62 and 1963-71, the error-learning hypothesis still must be rejected. Coefficients for this parameter over all three periods, however, differ by less than .01 , suggesting

${ }^{10}$ The one tailed test is appropriate for testing the null hypothesis that $b_{1}=0$ against the alternative hypothesis that $b_{i}>0$. that estimates from the shorter sample periods may be inefficient but unbiased estimates of the true parameter. ${ }^{11}$

Since the error-learning model implies that all information relevant to forecast revisions is contained in the most recent error, the significant negative coefficient on the constant term requires further discussion. The significance of these coefficients, together with the low coefficient of determination $\left(\mathbf{R}^{2}\right)$, could be interpreted as evidence that important variables have been omitted from the specification. A careful examination of the expectations formation process underlying equation 4 provides additional support for this interpretation.

As noted above, the relevant error-learning model should be derived from and consistent with the underlying structural expectations formation model. Recalling the definitions for the revision and the forecast error, it is easy to see that the underlying fore-

\footnotetext{
11The estimated coefficients for the three pre-1972 sample periods do not differ significantly from each other, suggesting that they are all unbiased estimators of the true parameter. Because the variance of these estimated coefficients tends to decline with increases in the size of the sample, the estimates for the shorter periods cannot be considered efficient (i.e., they are not the minimurn variance estimators). For a discussion of the efficiency of estimators, see Jan Kmenta, Elements of Econometrics (New York; MacMillan Publishing Company, 1971), pp. 157-69.
} 
cast mechanism implied by equation 4 conforms to the following relationships:

$$
\begin{aligned}
& \pi_{0, \mathbf{t}}^{*}=\mathbf{a}_{9}+\mathbf{a}_{1} \pi_{a_{,},}, \text {and } \\
& f_{\mathrm{a}, \mathrm{t}}=\alpha_{0}+\alpha_{1} \pi_{\mathrm{a}, \mathrm{a}}^{\mathrm{a}},
\end{aligned}
$$

where $a_{1}=\alpha_{1}$ and the t-subscripts identify the period in which the variable is observed. ${ }^{12}$ (For example, $\pi_{6, t}$ is the most recently observed six-month inflation rate.)

Equations 5a and 5b imply a highly restrictive ("naive") version of the expectations process. These specifications imply that the forecasters' expectations of inflation for the next period depend only on the most recently observed rate of inflation. No other information is incorporated. Note also that both equations specify a constant. A nonzero constant in either equation implies that some premium (or discount) is added to the impact of the current 6-month inflation rate to obtain the relevant 6 -month inflation forecasts.

\section{AN ALTEPNATIV RORECAST MECHANISM}

If the true underlying expectations formation mechanism is less restrictive or more complex than the one described by equations $5 a$ and $5 b$, then the revision equation given in equation 4 is misspecified. Recent studies of inflation expectations offer some evidence for this interpretation.

Pesando, in his study of the Livingston data, hypothesized an autoregressive scheme for the price forecasts. ${ }^{13}$ In another study of inflation forecasts based on different survey data, Kane and Malkiel emphasized the importance of including some retum-tonormality variable. ${ }^{14}$ The return-to-normality model implies that forecasters adjust their forecasts to some notion of the "normal" rate of inflation. Mullineaux also experimented with a variety of variables that could potentially influence inflation expectations and reported ". . . that inflation forecasts are systematically influenced by past inflation rates and past rates of money growth, but not by fiscal-policy-related variables. ..." Both the Kane-Malkiel and Mullineaux studies highlight the relevance of other informa-

\footnotetext{
12The revision equation (equation 4) is obtained by lagging each term in equation $5 \mathrm{~b}$ and subtracting from $5 \mathrm{a}$.

13Pesando, in "A Note on the Rationality," characterized the Livingston forecast by a highly restrictive autoregressive scheme.

14Kane and Malkiel, "A.utoregressive and Nonautoregressive Elements."

15Mullineaux, "Inflation Expectations and Money Growth," p. 160 .
}

tion in addition to the past rate of inflation in the formation of inflation expectations. The remainder of this article explores an alternative inflation expectations formation mechanism that is hypothesized to depend on both the time series of past inflation rates and on elements that embody a return-to-normality notion.

\section{A Retum-to-Nomalny Model}

The following mechanism is hypothesized for the expectations formation process:

(6a) $\pi_{j, t}^{0}=a_{0}+a_{1} \pi_{j, t-1}^{a}+a_{2} \pi_{f, t}+a_{2} \pi_{t,}^{n}$, and,

$$
\mathbf{f}_{1, \mathrm{t}}=\alpha_{0}+\alpha_{1} \pi_{\mathrm{t}}^{\mathrm{o}} \text {. }
$$

This process describes the current inflation forecast for the $j$-month horizon in terms of last period's forecast $\left(\pi_{j, i-1}^{*}\right)$, the most recently observed $j$-month inflation rate $\left(\pi_{j, t}\right)$, and the currently held expected normal rate of inflation $\left(\pi_{t}^{\mathrm{n}}\right)$. The implied forward rate of inflation, $f_{j, t}$ - the inflation rate expected to prevail for the $j$-month period beginning at the completion of the current $j$-month period - is hypothesized to equal the currently held forecast plus some premium (or discount), $\alpha_{0}$.

This specification of inflation expectations embodies both autoregressive and return-to-normality elements. ${ }^{16}$ The presence of a lagged dependent variable in equation $6 \mathrm{a}$ can also be interpreted as capturing the relevance of any inertia in the forecasts. The larger the coefficient, $a_{13}$, the more reluctant forecasters are to revise their expectations. The coefficient, $a_{2}$, which applies to the most recently observed inflation rate, measures the extent to which new information about inflation is deemed relevant for the current period's forecast. Finally, the coefficient, $a_{3}$, reflects the dependence of short-run inflation forecasts on the long-run normal rate of inflation.

Equation 6a can be rewritten in a form that captures the impact of past errors. Adding and sub-

16 For example, by repeated substitution for the lagged depend ent variable, equation $6 a$ can be shown to be equivalent to

$$
\begin{aligned}
& \pi_{j, t}^{a}=a_{0}+a_{2} \pi_{j, t}+a_{3} \pi_{t}^{n}+ \\
& \sum_{j=1}^{n} a_{1}\left(a_{3}+a_{2} \pi_{j, t-1}+a_{3} \pi_{t+1}^{*}\right),
\end{aligned}
$$

where the last term embodies primarily autoregressive components as well as the history of the normal rate of inflation. Another point merits attention. Suppose forecasts are macle for a minimum jumonth horizon and for other horizons that are some multiple of that horizon (for example, a 6-month, a 12-month, and an 18-month horizon). If each of these forecasts are made every j-month, then all forecasts, regardless of the horizon, can be represented as a distributed lag on past $j$-month inflation rates. 
tracting $a_{2} \pi_{6, t-1}$ from the right-hand side of $6 a$ produces:

(7) $\pi_{i, t}^{*}=a_{t}+\left(a_{1}+a_{2}\right) \pi_{1, t-1}^{a}+a_{2} E_{j, t}+a_{a} \pi_{t .}^{n}$

Lagging all terms in equation $6 \mathrm{~b}$ one period and subtracting from equation 7 produces a forecast revision equation that is consistent with this forecasting process:

(8) $R_{1, t}=\left(a_{0}-\alpha_{9}\right)+\left(a_{3}+a_{2}-\alpha_{1}\right) \pi_{3, t-1}^{*}+a_{2} E_{j, t}+a_{3} \pi_{t}^{n}$.

Clearly, the simple revision equation estimated by equation 4 is not consistent with the forecast mechanism described here. The correct equation for estimating revisions in such inflation expectations is:

$$
R_{1, t}=\beta_{0}+\beta_{1} \pi_{j, t-1}^{0}+\beta_{2} E_{j, t}+\beta_{3} \pi_{t}^{n}+u_{z} ;
$$

where $\beta_{0}=a_{0}-\alpha_{0}, \beta_{1}=\left(a_{1}+a_{2}-\alpha_{1}\right), \beta_{2}=a_{2}$, $\beta_{3}=a_{3}$, and $u_{t}$ is a random error. Note that the logic of the model implies that $a_{0}$ and $\alpha_{0}$ should be zero since all relevant information is presumed to be embodied in the variables $\pi_{j, t-1}^{*}, E_{j, t}$, and $\pi_{j}^{n}$. Consequently, estimated values of $\beta_{0}$ also should not differ significantly from zero.

The coefficient for the lagged dependent variable in equation $6 \mathrm{a}$ can be interpreted in terms of the speed with which forecasters adjust their expectations from one period to the next. Equation 6a describes the adjustment of inflation forecasts partly in terms of previously held forecasts. The size of the coefficient, $a_{1}$, on the lagged term measures the extent to which forecasters maintain previously held forecasts. The speed with which forecasts are adjusted over time, therefore, corresponds to $\left(1-a_{1}\right)$. Larger values for $a_{1}$ imply that a stronger persistence effect is embedded in the forecast process or, alternatively, that forecasts are revised more slowly when new information becomes available.

Finally, the degree of persistence evident in the forecasts could vary with the forecast horizon. Because information about permanent structural changes in the economy evolves only slowly and is costly to distinguish from transitory phenomena, long-run inflation expectations could be expected to change less from one period to the next than short-run expectations. As a result, longer-range forecasts should show greater persistence than shorter-range forecasts.

The hypothesized forecasting process described by equations $6 \mathrm{a}$ and $6 \mathrm{~b}$ contains a return-to-normality variable that reflects the view that forecasters incorporate information about the long-run expected inflation rate. This expected normal rate of inflation embodies relevant information from a wider variety of sources than simply the time series of past prices.
For example, Kane and Malkiel found that “. . . return-to-normality elements dominate forecasts of future inflation and [show] ... that developments outside the past history of prices importantly alter respondents' conceptions of what rate of inflation is "normal." "17 In their investigations of the return-tonormality hypothesis, Kane and Malkiel surveyed large firms and major bond dealers to gather inflation forecasts over several horizons. They were thereby able to calculate a normal rate forecast as a weighted average of subperiod forecasts which extended as far as 10 years into the future. Unfortunately, the Livingston data do not permit the derivation of any comparable and meaningful normal rate. Because the longest horizon forecast is only 18 months, a test of the return-to-normality hypothesis comparable to the Kane-Malkiel study is not possible. ${ }^{18}$ Consequently, tests of the return-to-normality hypothesis must rely on other measures of the normal rate of inflation.

One way to approximate the normal rate of inflation is to utilize some trend growth of the money stock. Such a proxy introduces a monetarist interpretation of inflation forecasts into the model namely, that the trend growth of prices is determined by the trend growth of money. ${ }^{19}$ In this study, a twenty-quarter moving average of past $\mathrm{M} 1$ growth is used as a proxy for the normal rate of inflation.

The use of a surrogate for the normal rate of inflation requires some modifications of the foregoing interpretation regarding equations $6 \mathrm{a}, 6 \mathrm{~b}$ and 9 . Suppose that equation $6 \mathrm{a}$ represents the true model that describes inflation expectations over some given short-run time horizon. If currently available information affects the actual rate of inflation only with some lag, then the forecast for the period beginning one period hence could differ from the forecast made for the period now beginning. To the extent that this currently available information is relevant to the long-run rate of inflation, it should be imbedded somehow in the normal rate of inflation. The proxy for the normal rate of inflation used here does not represent exactly the notion of the normal rate. For example, suppose the Federal Reserve announced that it intended to pursue a new money

17Kane and Malkiel, "Autoregressive and Nonautoregressive Elements," p. 3.

18These 18-month forecasts were collected only once each year and were discontinued after 1971 .

19See Denis Karnosky, "The Link Between Money and Prices - 1971-76," this Review (Jume 1976), pp. 17-23 for a discussion of the link between the trend growth of money and inflation. 
Table 3

Inflation Expectations: 6-Month Forecasts

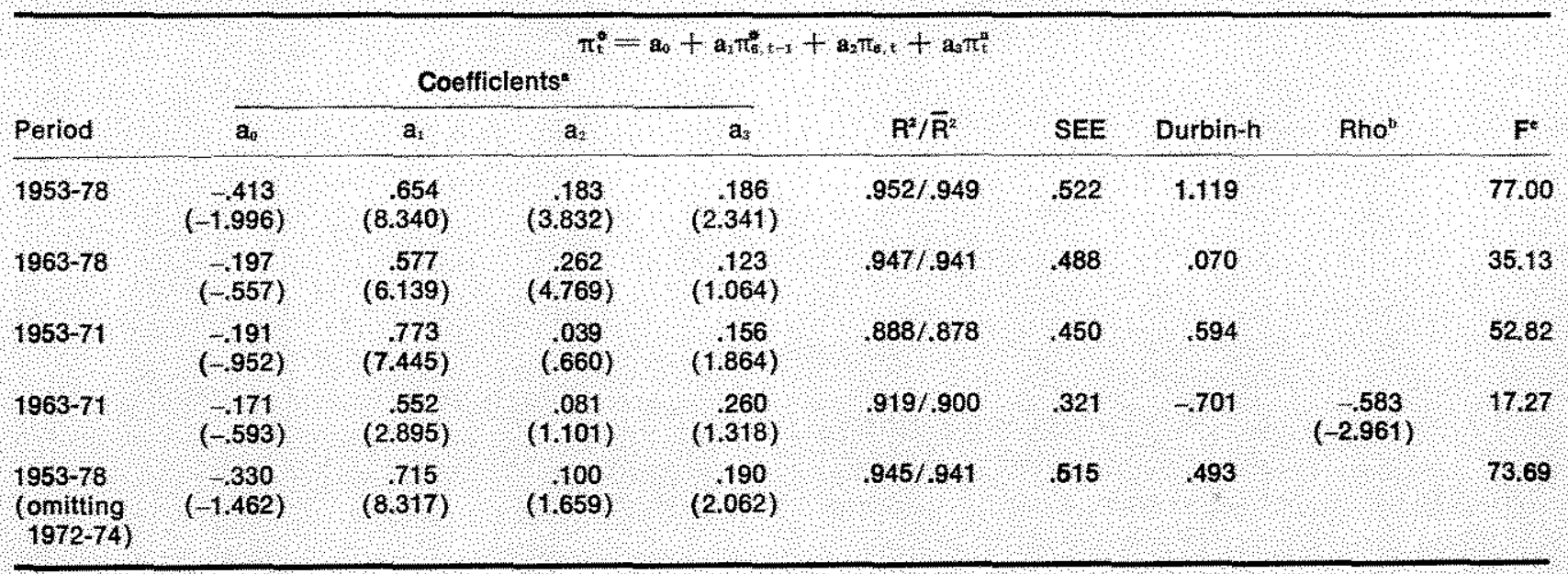

T-statistics are in parentheses.

The antocorrelation coefficient is teported only for that equation which was estimated by the Cochrane-Orout tedinigue because of evidence of serial correlation in the OLS estimates $t$-statistic is in parentheses.

F is the $\mathbf{F}$-statstie for assessing the hypothesis that the estimates reponted here do not differ from those obtaned by estinatIng the more simple model described by equation 5 a. The $F$ statistics permit rejection of this hypothesis at the 01 level for all time periods reported.

growth target over the coming six months. If this targeted growth rate differed from the previous trend growth of money, analysts might expect the trend in money growth to be changing during the current 6-month forecast horizon. Because the proxy for the normal rate used here is entirely "backward-looking," it omits such additional information. As a result, the implied forward rate equation could be expected to include additional terms. Since these terms are currently unmeasurable, however, they are assumed to be imbedded in the constant term; that is, the constant term in the implied forward inflation rate equation reflects the effect of currently available (but not measurable) information on the future inflation rate. A positive constant would reflect the forecasters' belief that the net effect of all other currently avail able and inflation-relevant information is to accelerate inflation. Finally, such a positive constant would imply a negative constant term, $\beta_{0}$, in equation 9 .

\section{Empirical Tests of the Alternative Inflation Forecast Model}

Tables 3 and 4 report the results of estimating equations $6 a$ and $6 b$, respectively, over various time periods. The first and perhaps most important observation is that the coefficients of determination $\left(R^{2}\right)$ in table 3 , are greater than 0.90 for four of the five periods. For longer periods, they exceed 0.94. This statistic indicates that over 90 percent of the variance of the inflation forecasts is explained by this relatively simple reduced form. Interestingly, these values for $\mathrm{R}^{2}$ are quite close to those obtained when the forecasts are estimated in terms of more complicated Almon lags on past inflation rates and past money growth. ${ }^{20}$ More importantly, the coefficients of determination adjusted for degrees of freedom $\left(\overline{\mathbf{R}}^{2}\right)$ are consistently greater than those obtained from estimates (not reported here) of the "naive" forecast equation given in 5a. The rejection of the naive model in favor of equation $6 \mathrm{a}$ is reinforced by $\mathrm{F}$-tests (for the hypothesis that the two equations do not differ) conducted for the various sample periods. Results of these tests (based on comparisons of ordinary least squares estimates of the two equations) are reported in the last column of table $3 .^{21}$ The alternative model is favored

\footnotetext{
20The adjusted $\overline{\mathrm{R}}^{2}$ s for equation $6 \mathrm{a}$ are similar to those obtained by Mullineaux. While the $\overline{\mathrm{R}}^{2} \mathrm{~s}$ reported here generally exceed those of Mullineaux, his sample period differed from those estimated here, making direct comparison inappropriate. Other estimations by the author of the inflation forecasts based on more complicated Almon lags of past money growth and past inflation rates did not generate consistently higher $\bar{R}^{2} s$ than did the equations reported here.

21 -tests were made on the basis of OLS estimations of the two equations. Cochrane-Orcutt estimations would involve transforming all observations by some coefficient of autocorrelation. Unless each equation is characterized by the same degree of serial correlation, the two equations would not be directly comparable.
} 
Table 4

Inflation Expectations: The Implied Forward Rate

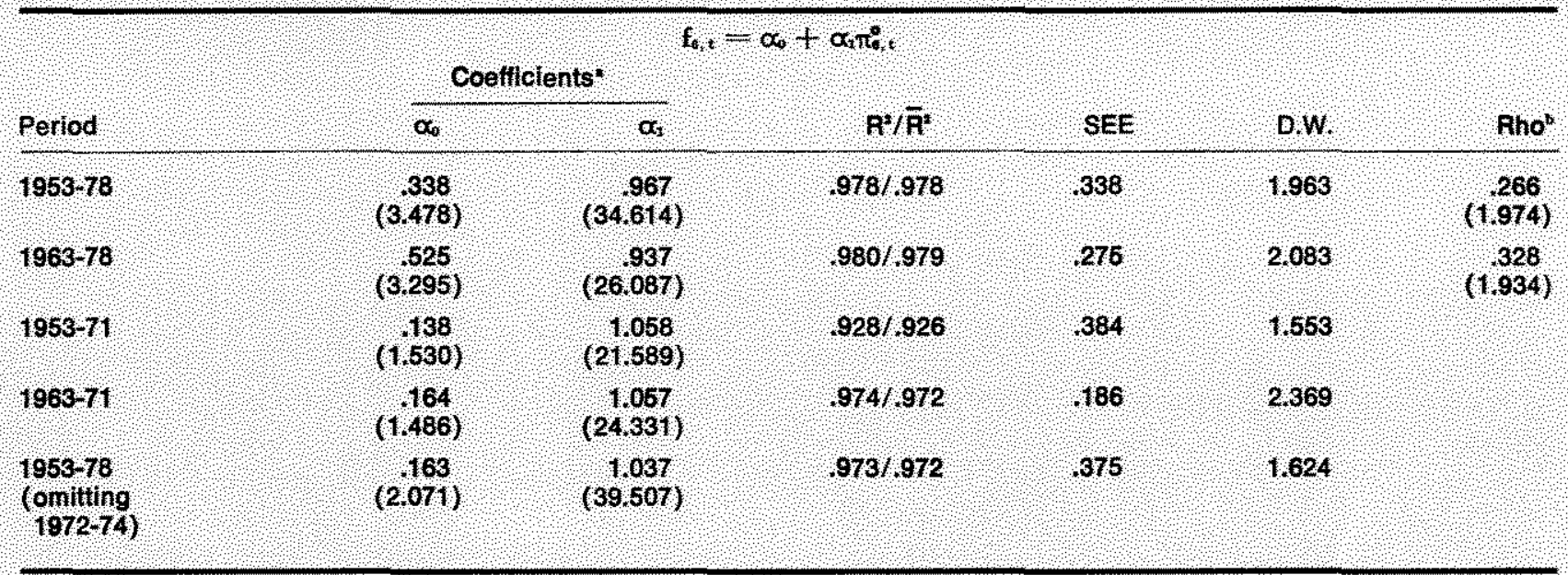

to statistics are in parentheses.

The antocorrelation coeffcient is reported only for those equations which were estimated by the Cochrane-Orcutt technique because of evidence of serial correlation in the OLS estimates, $t$-statisties are in parentieses.

over the naive model at the 0.01 confidence level for all time periods ${ }^{22}$

The estimated constants reported in table 3 reinforce the view that this forecast mechanism is more appropriate than the naive model. In estimates of that model, statistically significant, positive constant terms were consistently obtained, suggesting the importance of omitted variables. In contrast, estimates of the present model produced a significant (though negative) constant term in only one sample period - 1953-78. This constant could capture elements related to the era of the Nixon wage-price controls. When this three-year episode is deleted, the constant is no longer significant at standard confidence levels. Finally, it should be noted that, unlike the naive model, the present model shows no evidence of positive serial correlation, though the 1963-71 sample period shows some evidence of negative serial correlation. ${ }^{23}$ The implied forward rate

22In several OLS estimations of the naive model, the DurbinWatson statistic was unacceptably low. While this result is usually interpreted as evidence of positive serial correlation, it may also indicate that important explanatory variables have been omitted. This interpretation seems appropriate here, since by including the two additional variables in equation 6a, evidence of positive serial correlation disappears.

25The Durbin-h statistic is appropriate for testing for serial correlation when lagged values of the dependent variable are included. The Durbin-h is nomally distributed with a zero mean and a variance of $\sigma^{2}$, See J, Johnston, Econometric Methods (New York: McGraw-Hill, 1972), pp. 312-13. is also accurately described by equation $6 \mathrm{~b} .{ }^{24}$ Taken together, these results provide favorable evidence that the underlying forecast process conforms quite closely to the one hypothesized here.

Although the $\mathrm{R}^{2} \mathrm{~s}$ remain high over the various sample periods, the variation in the estimated coefficients, especially those for the current inflation rate and the normal rate, suggest that the contribution of these variables in the forecasting process has changed. ${ }^{25}$ For example, in periods ending with 1971, the current rate of inflation played virtually no independent role in the determination of next period's forecast. Apparently, current inflationary phenomena was largely discounted - at least until it became embedded in the past trend of inflation. As the sample period is extended toward the present, however, the most recent inflation rate assumes a dramatically different role. Both the magnitude and the significance of the $a_{2}$ term indicate that forecasters viewed the information reflected in the current inflation rate as more relevant.

\footnotetext{
24 Equation $6 \mathrm{~b}$ implies that the implied forward rate could alternatively be expressed in a form similar to that given in 6a. Estimating this version of the forward rate did not prom vide as good a fit in terms of $\mathrm{R}^{2}$ as did the more simple form.

25 Mullineaux, "Inflation Expectations and Money Growth" also observed a changing forecast structure over time. Mullineaux's work gives a thorough and detailed analysis of the behavior of the temporal coefficients on past inflation.
} 


\section{Table 5}

\section{Inflation Expectations: 12- and 18-Month Forecasts}

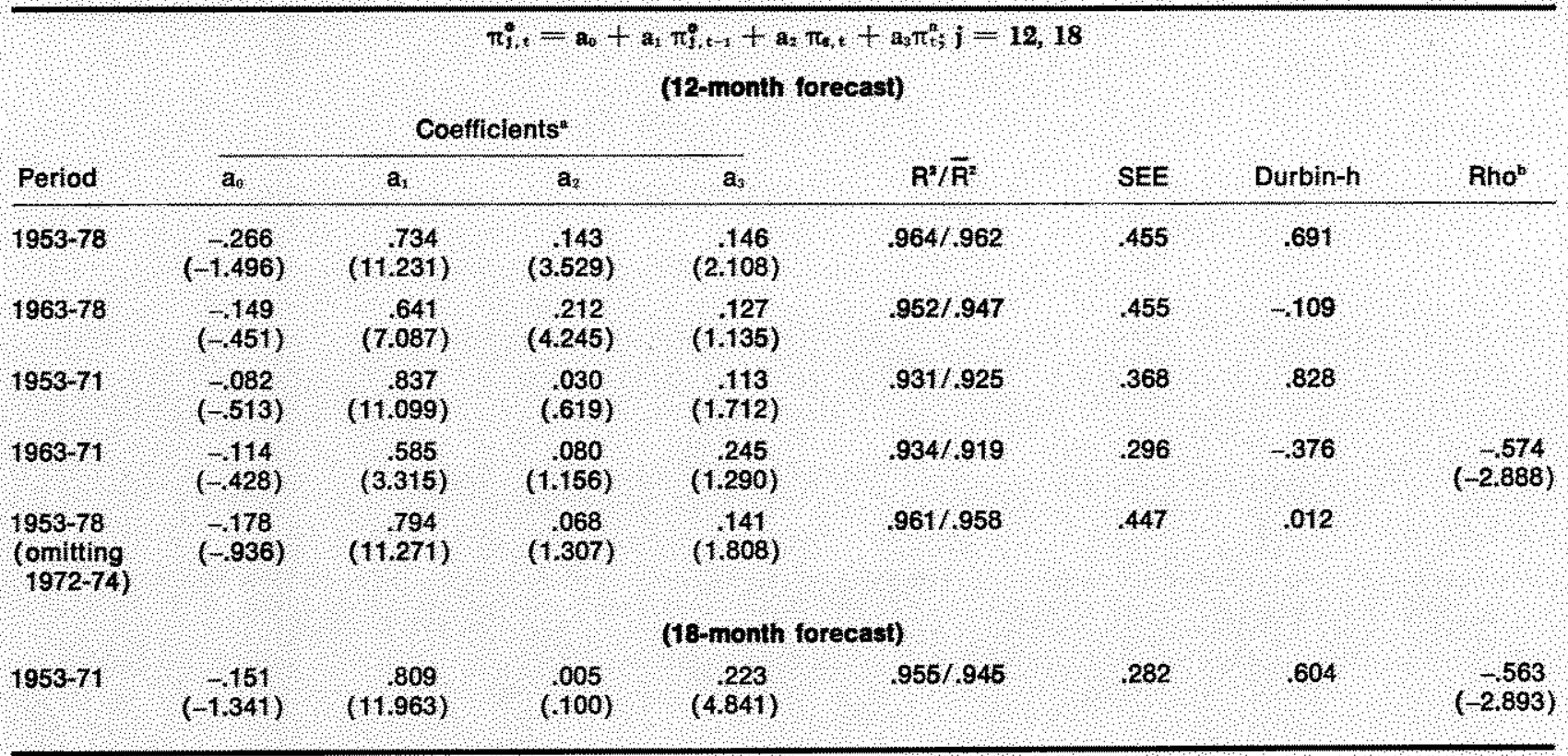

$r_{t}$ statistics are in parentheses.

The autocorrelation coefficient is teported only for flose equations which were estimated by the Cochrane-Orcutt technigue because of evidence of serial correlation in the OLS estimates, $t$-statistics are in parentheses.

Examination of estimates for equation $6 \mathrm{a}$ over longer forecast horizons offers an additional perspective. Table 5 reports estimates of equation 6 a for 12 and 18-month horizons. ${ }^{2}$ Estimated coefficients for the 12-month horizon over various time periods show a pattern similar to that estimated for the 6-month horizon. As expected, all coefficients on the lagged dependent variable are larger for the 12-month horizon than for the 6-month horizon. This suggests that there is greater period-to-period persistence and a slower adjustment speed in the 12-month forecasts than in the 6-month forecasts. For the 18-month forecasts, however, the coefficient on the lagged depend-

\footnotetext{
${ }^{26}$ Note that estimated equations for these forecast horizons differ slightly from those described by equation $6 a$ in that the most recent 6 -month inflation rate, rather than the most recent $12-$ or 18 -month inflation rates, is included. The reason for this is that the 12-month forecast, made six months ago, already incorporated all relevant information from past inflation. Only the most recent 6 -month inflation rate is "news." (As noted in footnote 16, all forecasts, regardless of horizon, can be represented as a distributed lag on past 6-month inflation rates.) If the 12 - and 18-month forecasts were made only every 12 and 18 months, then the exact specification given by $6 a$ would be appropriate. (Equation $6 \mathrm{a}$ was estimated using this latter specification, despite the informational redundancy contained in the 12 or 18 . month actual inflation rate. Those results did not differ notably from those reported here.)
}

ent variable was slightly (but not significantly) lower than in the 12-month forecast horizon.

For those time periods in which the most recently observed 6-month inflation rate significantly affected the forecasts, its impact was greater on the short-run (6-month) forecasts than on the longer-run (12month) forecasts. This observation provides further evidence that the most recently observed inflationary experience is incorporated only slowly into longer-run forecasts.

The specification given by equation $6 a$ permits a useful interpretation of the coefficient for the normal rate. Essentially, the long-run tendency for the $\mathrm{j}^{\text {th }}$ horizon forecast to converge toward the normal rate can be represented by a long-run coefficient on the normal rate described as $a_{3} /\left(1-a_{1}\right),{ }^{27}$ Table 6 reports calculations of this parameter for the three forecast horizons over several periods. This long-run return-

27 The presence of a lagged dependent variable makes equation $6 a$ similar to a stock-adjustment type of equation. The coefficient, $a_{1}$, in $6 a$ is interpreted as one minus the speed of adjustment of the forecast to the long-run "equilibrium" rate of inflation. The long-rum coefficient for any other variable in the equation can then be described as a ratio of the estimated short-run coefficient to the speed of adjustment, i.e., $\mathbf{a}_{3} /\left(\mathbf{1}-\mathbf{a}_{1}\right)$. 
Table 6

\section{Long-Run Response of Short-Term Expectations to Changes in the "Normal" Rate of Inflation ${ }^{2}$}

\begin{tabular}{|c|c|c|c|}
\hline Period & forecasts & $\begin{array}{l}12 \text {-month } \\
\text { forecasts }\end{array}$ & $\begin{array}{l}18 \text { month } \\
\text { lorecasts? }\end{array}$ \\
\hline $1953-78$ & $\begin{array}{l}538 \\
(2908)\end{array}$ & $\begin{array}{l}549 \\
(2614)\end{array}$ & \\
\hline $1963-78$ & $(1,202)$ & $(1326)$ & \\
\hline 195371 & $(2.095)$ & $\begin{array}{r}6993 \\
(1868)\end{array}$ & $\begin{array}{r}1,168 \\
(2.649)\end{array}$ \\
\hline 196971 & $\begin{array}{r}5.50 \\
(2.275)\end{array}$ & $(2,590)$ & \\
\hline $\begin{array}{l}1953-78 \\
(0 m i t t i n g \\
1972-74)\end{array}$ & $(25865)$ & $\begin{array}{r}6684 \\
(2.206)\end{array}$ & \\
\hline
\end{tabular}

Due to rounding, the calculated coefficients may differ silghtly from those calculated from results reported in tables 3 and 5

${ }^{b} t$-statisties are in parentheses. For a deseription of the meth odology used to calculate the variance of a, $/(1$ at $)$ used in caleulating the 1 statistics see Kmenta Elements of Econometrics, 144

to-normality coefficient should be higher for longer forecast horizons, since long-run expectations would tend to converge to the normal rate of inflation. As expected, these long-run coefficients are larger for the 12-month than for the 6-month forecasts. While the differences between the coefficients for these horizons are not great, the long-run coefficient for the 18-month horizon is larger and, in fact, does not differ significantly from unity. Thus it appears that the forecasters do tend to form longurun expectations in a manner consistent with the return-to-normality hypothesis. ${ }^{28}$

The estimated magnitude of this long-run coeffcient for both the 6- and 12-month horizons falls dramatically when the sample period includes only the $1960 \mathrm{~s}$ and the $1970 \mathrm{~s}^{29}$ This observation reinforces the view that the rapid acceleration in inflation experienced during the $1970 \mathrm{~s}$ has had an important effect on the way inflation expectations are formed. Throughout this period, rapidly rising inflation may have simultaneously induced forecasters to revise the

${ }_{28}$ The calculated long-run coefficients for the normal rate are comparable to those obtained by Kane and Malkiel in thei estimations based on cross-sectional data. For example, in equations using the CPI, their estimates of the return-tonormality coefficient ranged from about, 52 for the 6 -month horizon (in 1969) to about .63 for the 12-month horizon (in 1972).

29 Note that the coefficient deteriorates only slightly in the subsample 1963-71. normal rate of inflation more frequently. Hence, the proxy measure for the normal rate used here may understate the correct value of the normal rate, when inflation is accelerating rapidly. ${ }^{30}$ This possible measurement error could distort the evidence reflected in the long-run coefficient for this variable, especially during more recent periods.

In summary, several relevant observations emerge from the estimations of equations $6 a$ and $6 \mathrm{~b}$. The inflation forecasting process employed by respondents to Livingston's survey of economists can be described in terms of both autoregressive elements and past money growth (interpreted here as a proxy for returnto-normality elements). Nevertheless, although the equation performs well over all subsamples of the period $1953-78$, the relative roles played by the current and normal rates of inflation appear to have changed. Specifically, during the 1970 s when inflation accelerated sharply, return-to-normality elements played a less important role while the most recent rate of inflation became more important. Finally, the emergence during the $1970 \mathrm{~s}$ of a significant, positive constant in the implied forward rate equation provides some evidence that forecasters had begun to anticipate accelerating inflation.

\section{Implications for Error-Learning Models}

The relevant equation for examining the errorlearning hypothesis is implied by the underlying expectations formation process. Equation 9 satisfes this criteria. In addition to the forecast error, it includes a lagged inflation forecast term and a return-tonormality element. Table 7 reports statistics obtained from estimating this equation.

When the error-learning hypothesis is examined from the perspective implied by the forecast mechanism underlying equation 9 , evidence of error-learning is clearly present. The coefficient on the forecast error, $\beta_{z}$, differs significantly from zero at the 5 percent level (one-tailed test) over all sample periods except 1953-71. Recall that this coefficient reflects the relevance of the most recently experienced inflation. The results reported above reveal that the current rate of inflation only became important in samples that included the experience of the 1970s, during which inflation was accelerating sharply. Thus, Carlson's earlier conclusions about the relevance of past errors in ex-

30This view is reinforced by some results reported by Mullineaux. Using a two-period distributed lag on past 6 -month money growth, Mullineaux found that both lagged coefficients increased dramatically during the 1970 s. Thus, measures of "normal" inflation based on a fixed-weight average of past money growth would understate the "true" normal rate. 
Table 7

Revisions in Inflation Expectations: The Implied Model

\begin{tabular}{|c|c|c|c|c|c|c|c|c|}
\hline \multirow[b]{2}{*}{ Period } & \multicolumn{7}{|c|}{ 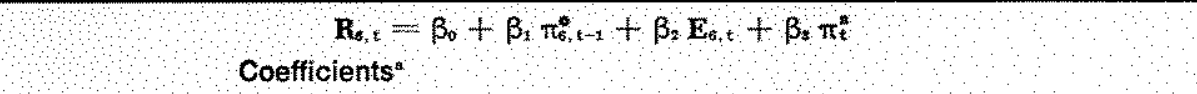 } & \multirow[b]{2}{*}{ Rho } \\
\hline & $\beta_{0}$ & $\beta_{1}$ & $\beta_{i}$ & $\beta_{3}$ & $\mathrm{~A}^{2} / \overline{\mathrm{A}}^{\mathrm{i}}$ & SEE & D.W & \\
\hline $1953-78$ & $\begin{array}{r}-553 \\
(-2.830)\end{array}$ & $(-2.932)$ & $\begin{array}{r}215 \\
(4.775)\end{array}$ & $\begin{array}{r}169 \\
(2.256)\end{array}$ & $402 / .365$ & .493 & 1.708 & \\
\hline $1963-78$ & $\begin{array}{r}-145 \\
-446)\end{array}$ & $(-394)$ & $\begin{array}{r}312 \\
(6.178)\end{array}$ & $\begin{array}{r}-.052 \\
(-489)\end{array}$ & $.585 / .541$ & .448 & 2.393 & \\
\hline $1953-71$ & $\begin{array}{r}-444 \\
(-2.711)\end{array}$ & $\begin{array}{r}-349 \\
(-4931)\end{array}$ & $\begin{array}{r}.050 \\
(1.039)\end{array}$ & $\begin{array}{r}245 \\
(3.595)\end{array}$ & $431 / 381$ & 366 & 1.674 & \\
\hline $1963-71$ & $\begin{array}{r}-153 \\
(-731)\end{array}$ & $\begin{array}{r}-289 \\
(-1,826)\end{array}$ & $\begin{array}{r}116 \\
(2.137)\end{array}$ & $\begin{array}{l}130 \\
(906)\end{array}$ & $564 / 463$ & 251 & 2,006 & $(-4.395)$ \\
\hline $\begin{array}{l}1953-78 \\
\text { (omitting } \\
1972-74)\end{array}$ & $\begin{array}{r}-544 \\
(-2.860)\end{array}$ & $\begin{array}{l}-254 \\
(-4,256)\end{array}$ & $\begin{array}{r}091 \\
(1,790)\end{array}$ & $\begin{array}{r}.238 \\
(3,069)\end{array}$ & $376 / .331$ & .434 & 1.622 & \\
\hline
\end{tabular}

o-statistics are in parentheses.

The autocorrelation coefficient is reported only for that equation which was estimated by the Cochrane-Orcutt technique because of evidence of serial correlation in the OLS estimates $t$-statistic is in parentheses.

plaining forecast revisions is, in one sense, reaffirmed. The error-learning hypothesis, however, appears to have greater validity when recent, unexpectedly rapid inflation has invalidated prior forecasts.

Equation 9 requires that the estimated coefficients conform to restrictions implied by the underlying forecast process. These restrictions, which are listed below equation 9 , were confirmed for all sample periods in the estimates of the revision equation. In no case did the coefficients from equation 9 differ significantly from the restricted values for those coefficients derived from the independent estimates of the underlying forecasting process.

\section{SUMMARY AND CONCLUSTONS}

The foregoing analysis and discussion has presented evidence concerning the nature of the inflation forecasting process implicit in the Livingston price expectations data. Although earlier conclusions about the relevance of the error-learning hypothesis may have been valid for certain periods over the past 25 years, they do not appear to be valid for the decade of the $1970 \mathrm{~s}$.

More important, however, is the information revealed about the nature of the inflation forecasting mechanism. Evidence reported here indicates that when inflation has been accelerating, recent inflationary experience becomes more important in the expectations process. This result suggests that policies which can successfully lower current inflation could reap important longer-run dividends by simultaneously inducing a reduction in inflation expectations. ${ }^{31}$ The results, however, also suggest that once the economy moves from high inflation to lower inflation, return-to-normality elements may become more important. Under a regime where planned, gradual reductions in the growth rate of money are announced and pursued, inflation expectations would seemingly adapt only slowly. On the other hand, if during periods of decelerating inflation, expectations become more responsive to current experience - as they were during periods of accelerating inflation - expectations may well adapt more rapidly. Evidence of strong persistence effects over all time periods suggests that breaking the inflation psychology necessarily involves a long-term commitment by policymakers to an antiinflation policy. Once such a policy is announced and undertaken, any decelerating inflation actually experienced should reinforce the adaptation to lower inflation expectations.

31This observation should not be interpreted as supporting incomes-policies since the adoption of price and wage controls could be expected to alter the structure of expectations formation. 